\title{
LA CARGA DE ESTABLECER \\ LAS EXCLUSIONES DEL CONTRATO DE SEGURO EN LA PRIMERA PÁGINA DE LA PÓLIZA*
}

\section{THE DUTY TO SET EXCLUSIONS \\ ON THE FIRST PAGE OF THE INSURANCE POLICY}

\author{
DANIEL VÁSQUEZ VEGA** \\ Fecha de recibo: 30 de octubre de 2020 \\ Fecha de aceptación: 20 de noviembre de 2020 \\ Disponible en línea: 30 de diciembre de 2020
}

Para citar este artículo/To cite this article

VÁsquez Vega, Daniel. La carga de establecer las exclusiones del contrato de seguro en la primera página de la póliza, 53 Rev.Ibero-Latinoam.Seguros, 15-38 (2020). https://doi. org/10.11144/Javeriana.ris53.ceec

doi.org/10.11144/Javeriana.ris53.ceec

\footnotetext{
* Artículo producto de investigación dogmática descriptiva-prescriptiva (lege data) no registrada formalmente como proyecto de investigación.

** Estudiante de doctorado en derecho (SJD) en la University of Minnesota Law School, Magister en Derecho (LLM) de la University College London, Magister en Derecho con énfasis en Responsabilidad Civil de la Universidad EAFIT, Especialista en Derecho de Seguros de la Pontificia Universidad Javeriana, Abogado de la Universidad CES. Profesor de planta de la Universidad EAFIT. Miembro del grupo de investigación Derecho y poder. Conjuez de la Sala Civil del Tribunal Superior de Medellín, Árbitro de la Cámara de Comercio de Medellín (lista B). Correo electrónico: dvasqu22@eafit.edu.co.
} 


\title{
RESUMEN
}

En el Estatuto Orgánico del Sistema Financiero (EOSF) y en otros instrumentos se establece que "las exclusiones deben figurar en la primera página de la póliza" "so pena de ineficacia de la estipulación respectiva". En este artículo analizo qué debe entenderse por póliza, cuáles son las exclusiones que deben figurar en su primera página, y qué sucede con las que no cumplen este requisito. Para dar respuesta a estas preguntas reviso la Circular Básica Jurídica que desarrolla el EOSF, la doctrina sobre la contratación mediante condiciones negociales generales, y los antecedentes legislativos de las normas analizadas. Concluyo que la regla del EOSF está regulando las condiciones negociales generales o clausulado del contrato de seguro y que consecuentemente aplica únicamente a las exclusiones generales, pudiendo las partes acordar exclusiones particulares cuya eficacia no está condicionada a ninguna formalidad.

Palabras clave: Condiciones negociales generales, Clausulado, Póliza de seguro, Exclusiones, Contrato de adhesión, Estatuto Orgánico del Sistema Financiero.

\begin{abstract}
The Colombian Financial System Statute (EOSF) and other legal instruments establish that exclusions must appear on the first page of the insurance policy in order to be enforceable. In this paper I analyze what should be understood by insurance policy in such context, which are the exclusions that must appear on its first page, and what happens with those that do not comply with this requirement. To answer these questions, I review the Circular Básica Juridica which contains regulation to implement the EOSF, the doctrine on standard form contracts, and the legislative history of the law being analyzed. I conclude that the EOSF's rule on exclusions pertains only to the exclusions contained in insurance standard forms and that additional exclusions can be made part of the contract as long as they are dickered terms.
\end{abstract}

Keywords: Standard forms, insurance policy, exclusions, contracts of adhesion. 


\section{INTRODUCCIÓN}

El 23 de mayo de 2002 Carlos Noé tomó un seguro de vida y designó como beneficiaria a su cónyuge, Martha del Socorro. Como es usual, la celebración del contrato de seguro estuvo antecedida por un periodo de negociación precontractual que incluyó, en el caso que nos ocupa, la suscripción por parte de Carlos Noé de un "anexo a la solicitud para el seguro de vida individual" mediante el cual hacía constar que aceptaba una exclusión que dejaba por fuera de la cobertura la muerte que tuviera su origen en lesiones causadas con arma cortante durante el primer año de vigencia del seguro ${ }^{1}$ :

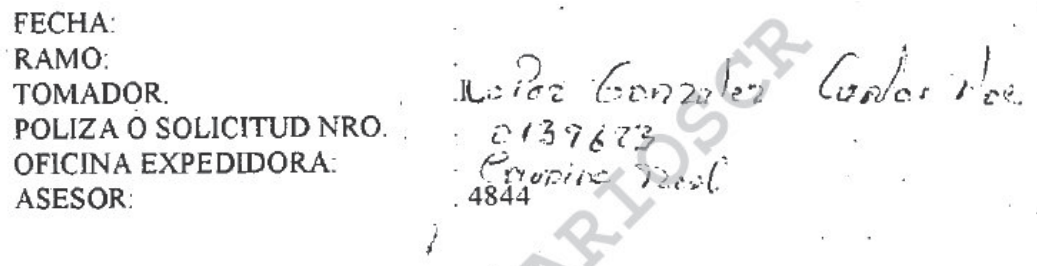

ANEXO A LA SOLICITUD PARA EL SEGURO DE VIDA INDIVIDUAL.

HAGO CONSTAR QUE ACEPTO LA EXCLUSIÓN DE LA COBERTURA DEL SEGURO DE VIDA Y DE LA EXONERACIÓN DE PAGO DE PRIMAS, DE LOS EVENTOS DE MUERTE O INVALIDEZ QUE TENGAN SU ORIGEN EN LESIONES CAUSADAS CON ARMA DE FUEGO, CORTANTE PUNZANTE O CONTUNDENTE DURANTE EL PRIMER AÑO DE VIGENCIA DEL SEGURO.

\section{LAS DEMAS CONDICIONES DEL SEGURO PRINCIPAL Y DELO ANEXOS QUEDARAN EN COMPLETA VIGENCIA.}

\section{Carías loprze.}

FIRMA DEL TOMADOR.

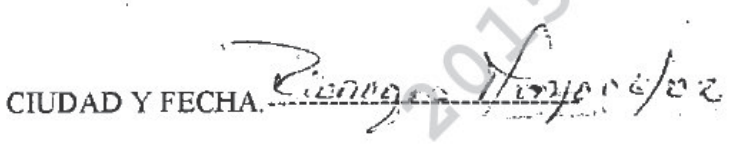

Casi un año después, el 3 de mayo de 2003, falleció Carlos Noé como consecuencia de unas lesiones causadas con un arma cortante y Martha del Socorro reclamó la indemnización contratada. La compañía de seguros objetó la reclamación indicando que, según el anexo ya referido, la muerte ocasionada por un arma cortante dentro del primer año de vigencia del seguro se encontraba excluida.

Descontenta con la decisión, la beneficiaria demandó a la compañía aseguradora. El juzgado de primera instancia indicó que, conforme a lo dispuesto en el art. 1048 del Código de Comercio, la solicitud de seguro, y por lo tanto también un anexo de la misma, eran partes de la póliza y que consecuentemente la exclusión era válida; sin

\footnotetext{
${ }^{1}$ La imagen del anexo me fue suministrada por Seguros de Vida Suramericana S.A., quien fue la compañía con la cual Carlos Noé tomó el seguro.
} 
embargo, también señaló que al haber cobrado una "prima completa", esto es, al no haber reducido la prima a pesar de haberse pactado dicha exclusión particular, entonces se debía entender que el seguro estaba cubriendo el riesgo que se pretendía dejar por fuera con la exclusión.

La demandada apeló la sentencia y el Tribunal Superior de Medellín revocó la decisión del juzgado indicando que no había lugar al pago de la indemnización por encontrarse excluido de la cobertura del seguro el evento que causó la muerte del señor Carlos Noé, pues consideró que la exclusión operaba independientemente de que no se hubiese modificado la prima.

No estando de acuerdo con la decisión, la demandante presentó una tutela en contra de la sentencia señalando que le había sido violado su derecho fundamental al debido proceso y a la defensa por haberse tenido en cuenta como prueba un anexo que contenía una exclusión ineficaz según lo dispuesto en el art. 184.2 del Decreto 663 de 1993, conocido como Estatuto Orgánico del Sistema Financiero (de ahora en adelante EOSF), toda vez que la exclusión no se encontraba en la primera página de la póliza.

La Corte Suprema de Justicia resolvió la tutela mediante sentencia de 29 de enero de $2015^{2}$ señalando que la decisión del Tribunal era contraria a derecho toda vez que, como lo indicaba la demandante, este había desconocido las normas que indican que las exclusiones, para ser eficaces, deben figurar en la primera página de la póliza (o a partir de ella en forma continua). La Corte, haciendo referencia a su sentencia de 25 de julio de $2013^{3}$, indicó que el EOSF hace

"la exigencia de consagrar, los amparos básicos y las exclusiones que se pactan en la póliza, en la primera página de la misma y no en las internas o en la carátula o en las condiciones generales, pues éstas últimas no se pueden identificar con la primera página de la póliza"4.

La Corte no indicó que debía entenderse por póliza, ni cuál era su primera página, simplemente señaló que esta no corresponde ni con la carátula, ni con las condiciones generales. La decisión fue confirmada por la Sala Laboral el 18 de marzo de $2015^{5}$.

En este artículo sostendré que la decisión de la Corte fue errada. El indicar que las exclusiones tenían que estar en la póliza y no en carátula o condiciones generales es incomprensible pues estos son los principales documentos que componen la póliza. A lo largo del texto explicaré por qué creo que la falencia de la Corte radica en pasar por alto que el contrato de seguro es un contrato celebrado mediante el uso de condiciones negociales generales y que es a estas a las que se refiere el art. 184.2 del EOSF y demás disposiciones que exigen que las exclusiones deben versar en la primera página de la póliza.

\footnotetext{
2 M. P. Margarita Cabello Blanco, STC514-2015.

3 M. P. Margarita Cabello Blanco, exp. 01591-00.

${ }_{4}$ Esto realmente lo no lo dijo la Corte en la sentencia de 2013, sino que consistía en un fragmento de una sentencia del Tribunal Superior de Valledupar que estaba siendo analizada en dicha ocasión, pero la Corte parece haberse confundido y lo cita como si se tratara de sus propias consideraciones.

5 M. P. Luis Gabriel Miranda Buelvas, STL3392-2015.
} 
A pesar de que esta sentencia fue proferida hace cinco años, su análisis aún resulta relevante porque ha sido reiterada en múltiples ocasiones ${ }^{6}$ y ninguna de las sentencias posteriores contiene consideraciones que rectifiquen o ayuden a aclarar la postura de la Corte; adicionalmente, tampoco ha habido reflexiones doctrinales sobre lo que se dispuso en la decisión. Así que, pretendiendo contribuir a llenar dicho vacío, en este escrito no solo sugiero los motivos por los cuales considero errónea la interpretación de la Corte, sino que expongo la que considero es la interpretación adecuada de las normas referidas.

Para esto, primero presento cuáles son las normas que, junto con el EOSF, establecen que las exclusiones deben ir en la primera página de la póliza so pena de ineficacia; luego explico en qué consiste la contratación mediante condiciones negociales generales, dado que entender este mecanismo permitirá interpretar adecuadamente las normas bajo análisis; más adelante presento la exposición de motivos de estas para, por último, pasar a su análisis. Esto permitirá responder qué debe entenderse por póliza, cuáles son las exclusiones que deben figurar en su primera página, y qué sucede con las exclusiones que no cumplen este requisito.

\section{NORMAS RELEVANTES}

De manera preliminar es necesario precisar cuáles son las disposiciones que contienen la regla bajo análisis, toda vez que ha sido consignada en más de una. La regla consistente en que "las exclusiones deben figurar en la primera página de la póliza" "so pena de ineficacia de la estipulación respectiva" se encuentra en el art. 44 de la Ley $\mathrm{N}^{\circ} 45$ de 1990 y el art. 184.2 del $\mathrm{EOSF}^{7}$, cuyos textos rezan:

Requisitos de las pólizas. Las pólizas deberán ajustarse a las siguientes exigencias:

1. Su contenido debe ceñirse a las normas que regulan el contrato de seguro, a la presente Ley [o estatuto, según el caso] y a las demás disposiciones imperativas que resulten aplicables, so pena de ineficacia de la estipulación respectiva.

$[\ldots]$

3o. Los amparos básicos y las exclusiones deben figurar, en caracteres destacados, en la primera página de la póliza.

Estas reglas fueron desarrolladas por la Circular Básica Jurídica (de ahora en adelante CBJ) 07 de 1996 de la hoy Superintendencia Financiera de Colombia, estableciéndose respecto de las pólizas de seguros lo siguiente:

\subsubsection{Requisitos generales de las pólizas de seguros}

Para el adecuado cumplimiento de lo señalado en el art. 184 numeral $2^{\circ}$ EOSF las entidades aseguradoras deben redactar las condiciones del contrato de forma que sean cla-

\footnotetext{
${ }^{6}$ Ver sentencia de 25 de octubre de 2017 (M.P. Ariel Salazar Ramírez, STC17390-2017), de 13 de diciembre de 2017 (M.P. Luis Gabriel Miranda Buelvas, STL21422-2017), de 10 de octubre de 2018 (M.P. Octavio Augusto Tejeiro Duque, STC13117-2018), de 04 de febrero de 2019 (M.P. Octavio Augusto Tejeiro Duque, STC941-2019), entre otras.

7 El art. 184.2 del EOSF reprodujo en términos idénticos lo dispuesto en la Ley $N^{\circ} 45$ de 1990.
} 
ramente legibles y que los tomadores y asegurados puedan comprender e identificar las definiciones de los riesgos amparados y las obligaciones emanadas del negocio celebrado. Para ello, las pólizas deben incluir, cuando menos, la siguiente información:

\subsubsection{En la carátula}

a. Las condiciones particulares previstas en el art. 1047 del Código de Comercio.

b. En caracteres destacados o resaltados (es decir que se distingan del resto del texto de la impresión) el contenido del inciso primero del art. 1068 Código de Comercio. Para el caso de los seguros de vida, el contenido del art. 1152 del mismo ordenamiento legal.

\subsubsection{A partir de la primera página de la póliza (amparos y exclusiones)}

Los amparos básicos y todas las exclusiones que se estipulen deben consignarse en forma continua a partir de la primera página de la póliza. Estas deben figurar en caracteres destacados o resaltados, según los mismos lineamientos atrás señalados y en términos claros y concisos que proporcionen al tomador la información precisa sobre el verdadero alcance de la cobertura contratada. No se pueden consignar en las páginas interiores o en cláusulas posteriores exclusiones adicionales en forma distinta a la prevista en este numeral.

Nótese como la CBJ hace referencia a un documento denominado póliza, del cual hace parte la carátula, pero luego también habla de nuevo de la póliza como si fuera un documento distinto a esta y menciona a los anexos como otro documento que también hace parte de la póliza. Esto es, la Circular denomina póliza tanto a la suma de documentos que contienen el contrato de seguro, como a un documento específico que, como mostraré más adelante, se identifica con las condiciones generales o clausulado del contrato de seguro.

La CBJ 07 de 1996 fue remplazada por la 029 de 2014 y en esta se reprodujeron de manera idéntica todas las disposiciones recién transcritas ${ }^{8}$.

En adición a estas normas, en el 2011 el Estatuto del Consumidor estableció en su art. 37 los requisitos mínimos que deben cumplir las condiciones negociales generales y los contratos de adhesión para ser eficaces, disponiéndose particularmente para el caso del contrato de seguro que "el asegurador hará entrega anticipada del clausulado al tomador, explicándole el contenido de la cobertura, de las exclusiones y de las garantías".

Sobre estas normas versa el análisis que sigue.

\footnotetext{
${ }^{8}$ Entre la CBJ 07 de 1996 y la CBJ 029 de 2014 hubo algunas modificaciones a la primera en las cuales se cambiaba el texto transcrito por:

Primera página de la póliza. En esta página deben figurar, en caracteres destacados, según los mismos lineamientos atrás señalados, y en términos claros y concisos que proporcionen al tomador la información precisa sobre el verdadero alcance de la cobertura contratada, los amparos básicos y todas y cada una de las exclusiones que se estipulen. Por ningún motivo se podrá consignar en las páginas interiores o en cláusulas posteriores exclusiones adicionales que no se hallen previstas en la primera condición aquí estipulada.

Sin embargo, como la CBJ 029 de 2014 regresó al texto original, en este análisis no tendré en cuenta estas modificaciones temporales. No obstante, queda la duda de por qué la Superintendencia ha ido alternando entre estos textos.
} 


\section{LOS CONTRATOS SOMETIDOS A CONDICIONES NEGOCIALES GENERALES}

Para comprender las normas que exigen que las exclusiones de un contrato de seguro figuren en la primera página de la póliza so pena de ineficacia, es necesario entender a los contratos de seguro como contratos sometidos a condiciones negociales generales y tener claridad sobre en qué consiste esta modalidad de contratación, cuáles son sus razones de ser y qué políticas públicas se han sugerido para contrarrestar los desequilibrios a los que pueden dar lugar.

El desarrollo de actividades empresariales a gran escala, así como la producción masificada a la que dio lugar la industrialización, permitió el desarrollo de un nuevo modelo de contratación, el cual, a diferencia de la contratación clásica, no se basaba en la negociación entre las partes de cada una de las cláusulas de su acuerdo, sino en la predisposición por una de las partes de los términos y condiciones que pretendía utilizar con un alto volumen de clientes quien luego negociaba con estos solamente los términos más relevantes del acuerdo (KESSLER, 1943) 9 .

La modalidad de contratación a través de condiciones negociales generales se refiere entonces a aquellos casos en los cuales una persona -jurídica en todos o casi todos los casos- crea un documento que contiene las condiciones bajo las cuales está dispuesta a celebrar un tipo de contrato que pretende celebrar con un número significativo de clientes o consumidores. Estos acuerdos serán contratos en los cuales los clientes interesados podrán aceptar o rechazar la oferta tal y como les es propuesto por la sociedad empresaria (esto es, contratos de adhesión en sentido estricto) o contratos en los cuales solamente podrán negociar algunos de los términos principales del mismo (esto es, contratos de adhesión en sentido ligero), pero en cualquier caso serán contratos regulados, en una medida altamente significativa, por las condiciones negociales generales que la empresaria creó $^{10}$.

Esta modalidad de contratación se ha vuelto la regla general en muchas industrias. Por ejemplo, es utilizada por las compañías de telefonía móvil en sus contratos de prestación de servicios de teléfono e internet para celulares; por las entidades bancarias para los diferentes tipos de contratos de mutuo y contratos financieros que ofrecen; y por las empresas de software que venden las licencias de uso para los distintos programas que crean. El sector asegurador no se escapa de esta práctica y es otra de las industrias

\footnotetext{
9 De manera similar Eduardo Polo ha indicado que las condiciones generales nacen como una respuesta jurídica a las necesidades técnicas surgidas de la contratación seriada o en masa típica de la economía capitalista, como un medio de racionalizar y simplificar la capacidad negocial de la empresa a través de fórmulas estereotipadas que permitan la realización idéntica y poco menos que simultánea de centenares o miles de contratos (Polo, Eduardo. "Protección del contratante débil y condiciones generales de los contratos", Madrid: Civitas, 1990, 31. En: PosADA, 2015, p. 151).

10 Aunque es posible establecer diferencias conceptuales entre los contratos sometidos a condiciones negociales generales y los contratos de adhesión, dada la frecuencia en la que coinciden, en ocasiones la doctrina (RAKOFF, 1983, pp. 1176-1177) e incluso la ley (ver el art. 37 de la Ley $N^{\circ} 1480$ de 2011) han utilizado las expresiones como si fueran sinónimas.
} 
que prototípicamente contrata haciendo uso de condiciones negociales generales, de hecho, está obligado por ley a hacer uso de ellas ${ }^{11}$.

Las razones que conducen al uso empresarial de condiciones negociales generales en la contratación han sido expuestas con claridad por Todd RAKOFF (1983, pp. 11201129). En primer lugar, señala, las condiciones negociales generales permiten reducir los costos en la celebración de contratos, minimizar la responsabilidad eventual de la sociedad y reducir la incertidumbre sobre cómo se encuentran regulados sus contratos $^{12}$. En segundo lugar, la estandarización de los términos facilita la coordinación entre los diferentes departamentos de una misma sociedad, reduciendo así costos de comunicación y de operación. La estandarización también permite hacer un uso eficiente del talento administrativo y jurídico de los empleados de la sociedad. Por último, las condiciones negociales generales permiten mantener bajo control a los departamentos de ventas, reduciéndoles su discreción a unos pocos términos modificables y evitando en gran medida que se celebren contratos bajo condiciones que la gerencia no está dispuesta a suscribir. Lo anterior implica que los contratos sometidos a condiciones negociales generales sean en la mayoría de las ocasiones contratos de adhesión (en sentido estricto o ligero).

Los clientes, señala RAKOFF (1983), son conscientes de esta realidad, saben que no resulta posible iniciar un proceso de negociación tendiente a modificar aquellas condiciones distintas a las que la sociedad ha predispuesto como negociables, e incluso si fuera posible, para la gran mayoría de ellos comparar condiciones generales es arduo, entran a estos acuerdos sin asesoría legal, muchas de sus cláusulas versan sobre cuestiones que difícilmente ocurrirán, no están en capacidad de evaluar estas contingencias, y los términos son largos y complejos, incluso si cada cláusula es estipulada con claridad. Así que RAKOFF concluye que lo razonable para el consumidor es "concentrarse en los pocos términos que son generalmente bien publicitados y de preocupación inmediata, e ignorar el resto” (p. 1226) ${ }^{13}$.

Bajo este escenario la publicidad o visibilidad de los términos importantes se vuelve clave, $\mathrm{y}$, como lo mostraré más adelante, es un pilar fundamental de la regulación que pretende evitar el mal uso de este mecanismo de contratación. Sin embargo, antes de pasar a ello, resulta importante preguntarse por qué han de considerarse vinculantes dichas condiciones cuando, en la gran mayoría de los casos, parece que ni siquiera son leídas por los clientes.

Al respecto, Randy BARNETT (2002, pp. 634-636) ha señalado que en sistemas en los cuales la base para justificar la fuerza vinculante de los contratos es el consentimiento

\footnotetext{
11 Así lo dispone la CBJ 029 de 2014 en su Parte II, Título IV, Capítulo II, art. 1.2.3.1.

12 A falta de cláusulas el contrato se encontrará, por supuesto, regulado en la ley, pero esta puede no ofrecer la claridad o certeza que la sociedad desea, por lo tanto, en la medida en que la ley sea disponible, la sociedad creerá obtener certeza si redacta los términos a su gusto.

13 La respuesta común de los consumidores termina siendo concentrarse en la reputación de la sociedad con quién han de contratar, más que en las condiciones negociales generales del contrato propuesto (p. 1227).
} 
a obligarse legalmente ${ }^{14}$-como es el caso del sistema jurídico colombiano ${ }^{15}$ - nada impide que una persona se obligue a algo aun desconociendo en qué consiste aquello a lo que se está obligando al momento de consentir. La autonomía privada permite asumir este tipo de obligaciones. Consecuentemente, continúa BARNETT, así como una persona se puede obligar a hacer aquello que se le ordene en un futuro sin que esto aún esté determinado, se puede obligar a someterse a unas condiciones contractuales, a pesar de desconocer qué se dispone en ellas. Obligarse de esta manera sin duda resulta más riesgoso que obligarse a sabiendas del compromiso que se está adquiriendo, pero nuestro derecho no proscribe la asunción de riesgos.

Esto, por supuesto, no implica que cualquier condición así pactada será válida. Los límites que nuestro ordenamiento dispone para cualquier contrato también aplicarán a aquellos celebrados mediante condiciones negociales generales. Esto impide la eficacia de las condiciones que constituyan un objeto o causa ilícita, que materialicen un dolo, o que, en general, fuesen en contra del orden público o las buenas costumbres, pero no implica que, en principio, lo allí dispuesto no sea eficaz.

En Colombia la incorporación al contrato y consecuente validez y efecto vinculante de estas condiciones se encuentra tácitamente reconocido por la Ley $\mathrm{N}^{\circ} 1480$ de 2011, conocida como el Estatuto del Consumidor, pues de no ser así, no tendría sentido el que en sus arts. 37, 42, 43 y otros similares, se dispusiera casos en los cuales las condiciones negociales generales, o las cláusulas abusivas contenidas en ellas, son ineficaces.

Dado entonces que por regla general se consideran que las condiciones negociales generales entran a formar parte del contrato entre la sociedad que las estipula y la cliente que las consiente, la doctrina ha sugerido la expedición de regulación que impida su uso abusivo (RAKoff, 1983, pp. 1206-1215). Por ejemplo, Arthur LeFF, en dos artículos publicados en $1970^{16}$, sostuvo que para combatir el mal uso de las condiciones negociales generales se debía, primero, exigirles a las sociedades que las utilizaban visibilidad de la información más relevante para el consumidor, y segundo, limitar el tipo de cláusulas o disposiciones que podían establecerse a través de las condiciones negociales generales, para garantizar así algunos derechos contractuales mínimos.

Esta fueron precisamente las políticas adoptadas por las ramas legislativa y ejecutiva colombianas ${ }^{17}$. Primero, enfocándose en información, se expidieron las normas que exigían que las cláusulas principales estuvieran en las primeras páginas, fueran visi-

\footnotetext{
14 Barnett, a diferencia de la mayoría de los doctrinantes de derecho contractual anglosajón (KLASS, Letsas, \& SAPraI, 2014), ha sostenido que es el consentimiento -y no las promesas- lo que justifica el que la judicatura sancione el incumplimiento contractual (BARNETT, 1986).

15 Ver art. 864 del Código de Comercio.

16 El primero de ellos fue Contract as thing (1970), el segundo Unconscionability and the crowd consumers and the common law tradition (1970).

17 Indira DíAz ha elaborado un recuento de las medidas adoptadas en diferentes países europeos y latinoamericanos, así como una comparación con las adoptadas en Colombia, en particular en lo tocante a las cláusulas modificativas de responsabilidad (2012, pp. 169 y ss.). La doctrina (JARAMILLO JARAMILLO, 2016a) ha dado un paso más al ocuparse también de proponer principios y reglas especiales de interpretación para las condiciones negociales generales, tanto individualmente consideradas, como en su relación con las condiciones individualmente acordadas.
} 
bles y comprensible -hablo precisamente de las normas que analizo en este artículo-, y luego, enfocándose en limitar aquello que vía condiciones negociales generales se podía estipular, se expidieron normas que prohibían algunos tipos de cláusulas, como sucede con la regulación para cláusulas abusivas. Para ambos casos se estipuló la ineficacia de las disposiciones que no se ajustaran a las normas.

Estas leyes pretenden que la cliente conozca o pueda conocer dichas condiciones negociales generales, porque si bien la negociación suele ser una oferta a la que se adhiere la tomadora sin posibilidad de discutir las condiciones del contrato, por lo menos debe ser consciente de las condiciones del contrato al que se está adhiriendo ${ }^{18}$. Como lo indica RAKOFF, dado que las clientes difícilmente leen o comprenden las condiciones negociales generales, se debe procurar que por lo menos se puedan dar por enteradas de los términos más importantes.

En la próxima sección muestro cómo la exposición de motivos de las leyes que contienen la norma bajo análisis confirma que efectivamente este era su propósito.

\section{FINALIDAD DE LA NORMA}

Según consta en los antecedentes de la Ley $N^{\circ} 45$ de 1990, el propósito de esta era solidificar, modificar y expandir los sectores financiero y asegurador, pero de tal manera que se garantizara la protección a los usuarios de estos. Para esto se daba pie a un proceso de desregularización para lo cual era necesario un fortalecimiento de los procesos de vigilancia y control.

En la ponencia para el primer debate en la Cámara de Representantes se señala que:

Al tiempo que la estructura de solvencia dinámica garantiza el adecuado flujo de recursos para que las entidades de seguros estén en capacidad de atender sus obligaciones, y que el cambio en el sistema de control y la libertad de pólizas y tarifas crea el ambiente preciso para garantizar la existencia de un mercado competitivo y eficiente, es necesario complementar este modelo con instrumentos que permitan a los tomadores y asegurados recibir un servicio cualitativamente eficiente y cristalizar las expectativas que los mueven a acudir a la industria.

Particularmente sobre el art. 44 -que contiene la regla que estoy analizando en este trabajo- dice que:

establece los requisitos generales que deben observar las pólizas, con el fin de subsanar prácticas inadecuadas de común ocurrencia en el mercado, que afectan la imagen del sector asegurador y perjudican los derechos de los asegurados. Así, se sanciona con la ineficacia la estipulación que contraríe las estipulaciones imperativas del con-

\footnotetext{
18 Se debe tener presente que por lo menos hasta que fue expedido el Estatuto del Consumidor, en Colombia la aseguradora no tenía la obligación de entregar y explicar las condiciones generales del contrato antes de su celebración, razón por la cual se podía presentar, y así sucedía efectivamente en la práctica, que la tomadora solo tuviese la oportunidad de conocer la totalidad de las condiciones que regulaban su relación con la compañía de seguros varios días después de ya haberse celebrado el contrato, pues las condiciones generales se incorporaban a este aún sin su conocimiento (OssA, 1991, pp. 258-261).
} 
trato de seguro, evitando que en las pólizas pueda mimetizarse requisitos para acceder al pago de las indemnizaciones, como por ejemplo sentencias ejecutoriadas, que no se compadecen con la libertad probatoria que establecen nuestros códigos. Debo llamar la atención sobre el hecho de que en ausencia de una sanción expedita como la ineficacia, que no requiere declaración judicial, la discusión sobre el alcance de la cláusula correspondiente debería llevarse a un proceso que toma varios años y que desmejoraría la posición del asegurado frente a la compañía.

Por las razones anteriores, el mismo art. 44 , en sus ordinales $2^{\circ}$ y $3^{\circ}$, establece normas de presentación para las pólizas, tratando de evitar dificultades de interpretación que suelen presentarse frecuentemente en relación con las coberturas y las exclusiones, con lo cual se facilita su comprensión para la comunidad. De esta manera se garantiza, en forma afortunada, el derecho de los terceros a conocer realmente el producto que compra a una compañía de seguros y a ejercitar debidamente los derechos que de ese contrato se derivan.

Adicionalmente y reiterando lo anterior, en la ponencia para el primer debate en el Senado, después de señalar que antes de la ley las pólizas eran uniformes para todas las compañías, se indica que

la reformulación de algunas normas del contrato de seguro plantea un régimen tendiente a eliminar nocivas prácticas que hoy fomentan la desconfianza en el sector asegurador y desdicen de su genuina finalidad de atender pronta y cumplidamente los siniestro. En desarrollo de esta idea deseo resaltar los requisitos expresos a los cuales deberán ajustarse las pólizas, por manera que el asegurado conozca a ciencia cierta los amparos básicos y las exclusiones que contempla determinada póliza.

Es tajantemente claro que la finalidad de la norma era procurar que la tomadora conociese a ciencia cierta la cobertura que se desprendía del contrato de seguro que pretendía celebrar. Y así incluso ha sido reconocido por la Corte Suprema de Justicia, que en sentencia de 19 de diciembre de $2008^{19}$ indicó que el literal c), numeral 2 del art. 184 del Estatuto Orgánico del Sistema Financiero establece que los amparos y las exclusiones que se establezcan en el contrato de seguro deberán figurar en caracteres destacados en la primera página de la póliza con el fin de que el tomador tenga información precisa sobre el verdadero alcance de la cobertura que contrata.

De la misma manera, el Tribunal Superior de Bucaramanga en sentencia de 8 de mayo de $2013^{20}$ indicó que al estar la póliza compuesta por la carátula y las condiciones generales del seguro y contener estas últimas a partir de su primera página y en forma consecutiva las coberturas y exclusiones se

"cumple la finalidad del legislador, que no es otra que sea claramente legible y comprensible, esto es, que el tomador y la víctima, al tener la póliza en sus manos identifiquen de manera clara y sencilla qué es lo que se ampara y qué es lo que está excluido"21.

\footnotetext{
19 M. P. Arturo Solarte Rodríguez, ref.: 11001-3103-012-2000-00075-01. La sentencia versaba sobre una controversia en la que se debatía cómo debía interpretarse una exclusión establecida en las condiciones negociales generales

20 M. P. Mery Esmeralda Agón Amado, rad. 68001-31-03-010-2009-00364-01.

${ }^{21}$ El reconocimiento de la teleología de la norma no se ha circunscrito a la justicia ordinaria, sino que también en sede arbitral ha sido tenida en cuenta. Así, en el laudo Corporación Club el Nogal vs. Chubb de Colombia Compañía de Seguros S.A., y Mapfre Seguros Generales de Colombia S.A. de 15 de marzo de
} 
Y de igual manera la Superintendencia Financiera de Colombia en concepto 1999055614-2 de 9 de febrero de 2000 indicó que las coberturas y exclusiones deberán figurar en caracteres destacados en la primera página de la póliza con el fin de proporcionar al tomador la información precisa sobre el verdadero alcance de la cobertura contratada, a efecto de que las partes en caso de duda puedan precisar el alcance de dichas estipulaciones, sin perjuicio de la posibilidad de acudir ante la jurisdicción ordinaria, la cual por la naturaleza de sus funciones es la competente para conocer sobre la materia.

Todo lo anterior permite concluir que la intención o espíritu de la regla que se analiza es que, como lo señaló Rakoff, los consumidores, en este caso tomadoras y aseguradas, conozcan o puedan conocer con facilidad los términos de preocupación inmediata, que en los contratos de seguro son la cobertura y sus limitaciones.

\section{PROBLEMAS INTERPRETATIVOS}

¿Dónde se origina entonces la confusión que condujo a que la Corte dijera que las exclusiones debían ir en la primera página de la póliza y no en las condiciones generales o clausulado? Pues el problema surge de que en la ley se ha utilizado la palabra póliza con distintos sentidos, lo cual se presta para ambigüedades que terminan en errores interpretativos como el cometido por la Corte en la sentencia referida en la introducción. Para resolverlo, es necesario desentrañar cuáles son los diferentes sentidos con los que se usa el término póliza y evidenciar por qué en el contexto de la regla que exige que las exclusiones vayan en la primera página de esta, el término se está refiriendo a las condiciones negociales generales.

\section{A. ¿Qué debe entenderse por póliza?}

La póliza, según lo dispuesto en el art. 1046 del Código de Comercio, es el documento contentivo del contrato de seguro y debe expresar las condiciones generales del contrato, así como las condiciones particulares que lo individualizan y permiten distinguirlo de otros contratos de seguro celebrados por las mismas partes o por partes diferentes, así como las demás condiciones particulares que pacten las partes.

Las condiciones particulares mínimas son el nombre de las partes, los nombres de la asegurada y de la beneficiaria si fueren distintos de la tomadora, la calidad en que actúe la tomadora del seguro, la identificación precisa de la cosa o persona con respecto a las cuales se contrata el seguro, la vigencia del contrato, la suma asegurada, la prima, los riesgos que la aseguradora toma su cargo, la fecha en que se extiende y la firma de la aseguradora (art. 1047 del C. Co.). Estas condiciones particulares mínimas, según la

2006, el Tribunal indicó que "el propósito perseguido por el legislador al establecer esa causal de ineficacia $[\ldots]$ consiste en que el asegurado reciba información clara, suficiente y oportuna sobre el ámbito preciso del amparo", y que si, como se explicará más adelante, se cumple este propósito por mecanismos diferentes a establecer las exclusiones en la primera página de la póliza, dicha limitación podrá valer. 
CBJ 029 de 2014, van en un documento denominado carátula, el cual también debe indicar, según lo dispuesto en la misma Circular y en el art. 1068 del Código de Comercio, que la mora en el pago de la prima produce la terminación automática del contrato.

Si, como se señaló, la póliza es el documento contentivo del contrato de seguro y la carátula es el que contiene las condiciones particulares mínimas indicadas en el art. 1047 del Código de Comercio, entonces la carátula es un documento que hace parte de la póliza. Lo anterior se confirma porque la regulación del contenido de la carátula en la CBJ 029 de 2014 hace parte de la regulación de los "requisitos generales de las pólizas de seguros". A pesar de esto la Circular, justo después de haber regulado qué debe contener la carátula, indica qué debe figurar a "partir de la primera página de la póliza", reiterando lo dispuesto en el EOSF sobre que allí deben ir "los amparos básicos y todas las exclusiones que se estipulen deben consignarse en forma continua a partir de la primera página de la póliza”.

Lo anterior parece contradictorio, pues por un lado parecería dar a entender que la carátula hace parte de la póliza, pero luego por otro lado parecería dar a entender que no es así. La confusión se acrecienta cuando, con miras a dar cumplimiento al depósito dispuesto en el parágrafo del art. 1047 del Código de Comercio, la CBJ habla del depósito de la póliza y del depósito de la carátula como si fueran documentos diferentes.

La solución a esta aparente contradicción es interpretar que la ley utiliza el término póliza para hacer referencia a dos documentos diferentes: en unos casos, como lo hace el art. 1046 del Código de Comercio, a un documento macro compuesto por todos los documentos que sumados contienen la totalidad del contrato de seguro (incluyendo en este caso la carátula); y, en otros casos, como lo hace el parágrafo del art. 1047 del Código de Comercio y la CBJ 029 de 2014, a un documento específico que contiene las condiciones generales del seguro, documento que en el art. 37 del Estatuto del Consumidor es denominado como condiciones negociales generales o clausulado.

La póliza, en sentido macro, además de la carátula y de las condiciones negociales generales (o póliza en sentido restringido), está compuesta por (a) las demás condiciones particulares que acuerden los contratantes (art. 1047 del C. Co.), condiciones particulares que en la práctica, dependiendo de su extensión, van al final de la carátula o en un documento independiente; (b) la solicitud de seguro firmada por la tomadora; y (c) los anexos que se emitan para adicionar, modificar, suspender, renovar o revocar la póliza (art. 1048 del C. Co.), anexos cuyo único requisito es indicar la identidad precisa de la póliza -o más bien del seguro-a que acceden (art. 1049 del C. Co. y CBJ 029 de 2014).

En la práctica también se suela llamar anexo a algunas coberturas opcionales que complementan la cobertura básica y que constan en un documento aparte al que contiene las condiciones generales de la cobertura básica ${ }^{22}$. Práctica particularmente común en los seguros de vida a largo plazo en los cuales, al ser irrevocables y por ende inmodificables en su amparo básico, las coberturas opcionales se entregan en un docu-

${ }^{22}$ Este parece ser el uso que el parágrafo del art. 1047 del Código de Comercio da al término anexo. 
mento independiente para que luego, si es modificado, simplemente se deba cambiar este y no todas las condiciones generales (o póliza en sentido restringido).

Habiendo aclarado los significados del término póliza, es necesario resolver una segunda cuestión: ¿en qué sentido debe entenderse el término póliza cuando la regla establecida en el EOSF y la CBJ indica que "las exclusiones deben figurar en la primera página de la póliza o en forma continua a partir de la primera página de la póliza"? ¿En sentido macro o en sentido restringido?

Sobre este punto, como lo indiqué en la introducción, la Corte Suprema de Justicia, en sentencia de tutela de 29 de enero de 2015 afirmó que las normas en cuestión exigen consagrar las exclusiones en la primera página de la póliza "y no en las internas o en la carátula o en las condiciones generales, pues éstas últimas no se pueden identificar con la primera página de la póliza”.

Respetuosamente disiento de la afirmación de la Corte. ¿Qué opción deja el indicar que las exclusiones deben ir en la primera página de la póliza y no en la carátula o en las condiciones generales de la misma? ¿Qué sería entonces la póliza si no es los documentos que la componen? Considero que las únicas opciones interpretativas que permite la ley son que las exclusiones deban ir en la primera página de la carátula, como uno de los documentos integrantes de la póliza en su sentido macro, o en la primera página de las condiciones generales, que constituye la póliza en sentido restringido.

Y, entre estas dos opciones interpretativas, la correcta es la segunda. Esto se debe, por un lado, al origen de la regla y las explicaciones sobre la contratación mediante condiciones negociales generales; $y$, por otro lado, a que, en desarrollo del EOSF, cuando la CBJ 029 de 2014 indica que "las exclusiones que se estipulen deben consignarse en forma continua a partir de la primera página de la póliza”, lo hace en los apartes en los cuales está regulando la póliza en sentido restringido y no cuando regula la carátula, la póliza en sentido macro o cuando regula algún otro documento que hace parte de esta. Esto, además, se confirma al evidenciarse que, en la práctica, es en los clausulados en los cuales las compañías de seguros describen las coberturas y exclusiones que aplican, por regla general, a los contratos que celebran, sin que la práctica haya sido censurada por la Superintendencia Financiera de Colombia.

Y es que no podría ser de otra manera porque se trata de un caso de contratación vía condiciones negociales generales. El contrato de seguro, como cualquier otro contrato, es, en últimas, un acuerdo de voluntades orientado a permitir el intercambio de bienes y servicios (en el caso específico de los seguros, la transferencia de riesgos a cambio del pago de una prima). Los contratos, así entendidos, no requieren, por regla general, que el acuerdo sea expresado o se encuentre vertido en alguna formalidad o solemnidad específica para que produzca efectos ${ }^{23}$. ¿Por qué entonces las exclusiones sí tendrían que cumplir con una formalidad específica? Pues porque la ley se está refiriendo a exclusiones que no están siendo negociadas y acordadas una a una por las partes, sino que se trata de exclusiones que están siendo incorporadas mediante

\footnotetext{
${ }^{23}$ Así lo establece el art. 824 del Código de Comercio como regla general y es reiterado para el caso del contrato de seguro en el art. 1036 del mismo código.
} 
condiciones negociales generales y, si bien el legislador ha permitido esta modalidad de contratación, ha requerido que estos casos el consumidor tenga la oportunidad de conocer por lo menos los términos más importantes contenidos en dichas condiciones -que para el caso de los seguros son las coberturas y exclusiones- y cree que esto se logra requiriendo que dichos términos figuren en la primera página de las condiciones generales en caracteres destacados.

Así, frente a la pregunta ¿qué debe entenderse por póliza en la regla bajo estudio? La respuesta es la póliza en su sentido restringido, esto es, las condiciones generales o clausulado ${ }^{24}$.

\section{B. ¿En la primera página o a partir de ella?}

Ahora bien, como lo había indicado, el EOSF se encuentra desarrollado por la CBJ $0292014 \mathrm{y}$, si bien parecen establecer lo mismo, hay una diferencia evidente en su texto: mientras que el EOSF dispone que las exclusiones deben ir en la primera página de la póliza, la Circular indica que deben consignarse en forma continua a partir de su primera página. ¿Cómo se resuelve la diferencia? ¿Son disposiciones contradictorias o complementarias? ¿La Circular implica que cuando no sea posible que todas las exclusiones figuren en la primera página se puede continuar en las siguientes?

Considero que la respuesta a estos interrogantes se encuentra en el principio general del derecho consistente en que nadie está obligado a lo imposible ${ }^{25}$. El art. 1518 del Código Civil indica que cuando el objeto de una obligación es un hecho, como lo es en el caso que nos ocupa, este debe ser posible, por lo tanto, así se tuviese en cuenta únicamente el EOSF, cuando no sea posible incluir en la primera página todas las exclusiones en caracteres destacados - que como lo indica la Circular es lo que significa que se distingan del resto del texto- pues entonces necesariamente se deberá continuar en las páginas siguientes.

En este sentido, más que contradecir el EOSF, lo que hace la CBJ 029 de 2014 es simplemente volver explícito lo que implícitamente se hubiese derivado del hecho de no estar obligado a lo imposible, dejando claro, además, la forma de hacerlo: de manera continua y sin esconder las exclusiones en otras cláusulas ${ }^{26}$.

A una conclusión similar han arribado algunos jueces, como por ejemplo el Tribunal Superior de Bucaramanga, que en sentencia de 29 de mayo de $2013^{27}$ indicó que, si las exclusiones son tan extensas que no caben en la primera página de la póliza, en ella se debe hacer una remisión o alusión a las demás exclusiones. En sentido similar el mismo

\footnotetext{
${ }^{24}$ El análisis y conclusiones hasta aquí expuesto comulga con la opinión manifestada por la Superintendencia Financiera de Colombia en concepto 19980446555 de 17 de agosto de 1999. Si bien el concepto se refiere a la CBJ 07 de 1996, en la medida en que los apartes referidos no fueron modificados por la CBJ 029 de 2014, lo establecido en él se mantiene vigente.

25 Este principio se desprende en Colombia de los arts. 1502 y 1518 del Código Civil.

26 Esta conclusión comulga con la opinión manifestada por la Superintendencia Financiera de Colombia en la respuesta de 4 de febrero de 2020 a una consulta específica que recibió, rad. 2019153273-007-000.

27 M. P. Claudia Yolanda Rodríguez Rodríguez, rad. 2010-0029-01.
} 
Tribunal, en la ya referida sentencia de 8 de mayo de 2013, indicó que al estar la póliza compuesta por la carátula y las condiciones generales del seguro y contener estas últimas a partir de su primera página y en forma consecutiva las coberturas y exclusiones se cumple la finalidad del legislador, que no es otra que sea claramente legible y comprensible, esto es, que el tomador y la víctima, al tener la póliza en sus manos identifiquen de manera clara y sencilla qué es lo que se ampara y qué es lo que está excluido.

Concuerdo con el Tribunal Superior que la finalidad de la norma se sigue alcanzando cuando se permite que las exclusiones que no caben en la primera página de las condiciones generales continúen en las páginas siguientes, siempre y cuando sea de manera continua, como lo requiere la CBJ.

\section{C. ¿Todas las exclusiones deben figurar en la primera página de la póliza (o a partir de ella de forma continua)?}

Las exclusiones de los contratos de seguros son, según la clasificación establecida en el art. 1501 del Código Civil, elementos accidentales de los mismos ${ }^{28}$. Su propósito es delimitar el riesgo que la aseguradora asume en virtud del contrato de seguro y por lo tanto constituyen un ejercicio del arbitrio que, de acuerdo con el art. 1056 del Código de Comercio, tiene la aseguradora al momento de definir cuáles riesgos asume y cuáles no.

La regla dispuesta en el art. 184.2 del EOSF que se viene analizando establece que "las exclusiones deben figurar en la primera página de la póliza o en forma continua a partir de la primera página de la póliza" "so pena de ineficacia de la estipulación respectiva". ¿Pero cuál es el alcance de esta afirmación respecto de las exclusiones? ¿Significa que para que una exclusión sea válida debe figurar en las condiciones generales o a partir de ella de forma continua? (Primera interpretación) ¿O significa que las exclusiones que figuran en dichas condiciones deberán hacerlo en la primera página, sin que esto sea óbice para que se pacte válidamente exclusiones adicionales que figuren en documentos diferentes? (Segunda interpretación) ¿Qué sucede con las exclusiones que no figuran en la póliza entendida esta en sentido restringido (i.e. en las condiciones generales)?

De las dos interpretaciones, considero que la correcta es la segunda, esto es, la regla no implica que todas las exclusiones deban ir en la primera página de las condiciones generales, sino que aquellas que se consignan en ellas, para ser eficaces, deben ir en la primera página, sin que ello signifique que no pueda haber exclusiones por fuera del clausulado. Llego a esta conclusión por varias razones: (i) por concluir, como ya lo argumenté, que por póliza la regla se refiere a las condiciones generales o clausulado; (ii) por el arbitrio concedido la aseguradora para delimitar el riesgo que desea asumir; y (iii) por la finalidad informativa que tiene la regla bajo análisis. Adicionalmente, si bien no justifican la conclusión, esta se ve reforzada por (iv) el que el contrato de se-

\footnotetext{
${ }_{28}$ Excepcionalmente algunas son elementos de la naturaleza, como las establecidas en el art. 1104 y 1105 del Código de Comercio, pero de resto se trata de limitaciones al elemento esencial riesgo que pueden pactarse o no al momento de celebrarse el contrato.
} 
guro haya pasado de ser solemne a ser meramente consensual; y por (v) la nueva disposición incluida en el Estatuto del Consumidor respecto de los clausulados. Veamos:

\section{(i) Por entender que la póliza son las condiciones generales}

Como lo indiqué, póliza, en el contexto de la regla analizada, significa las condiciones generales. De manera consecuente, las exclusiones que deben ir en la primera página de este documento no pueden ser todas aquellas que delimiten el riesgo a ser asumido por el asegurador, sino solamente aquellas exclusiones generales a todas las aseguradas que tomen el seguro al que aplican dichas condiciones.

Al tratarse el seguro de un contrato que por su naturaleza se celebra de manera masiva $^{29}$, es necesario para simplificar el proceso de negociación acudir a la figura de la contratación mediante condiciones negociales generales que aplicarán a todos los tomadores que lo contraten. En estos casos el acuerdo de voluntades versa solamente sobre los elementos que particularizan del contrato -que como indiqué figurarán en la carátula- (OssA, 1991, pp. 253-258), y aplicarán las condiciones generales que la compañía de seguros tenga para el seguro suscrito siempre y cuando cumplan con los requisitos establecidos en el EOSF y en la CBJ.

Lo anterior, sin embargo, no puede ser impedimento para que la aseguradora que desee establecer en casos puntuales exclusiones adicionales a aquellas dispuestas en el clausulado, las pueda pactar con la tomadora. Pero por la naturaleza misma de las condiciones generales, será imposible que las exclusiones figuren en este documento. Dichas exclusiones adicionales podrán figurar en otros documentos y serán válidas siempre y cuando sean negociadas y la voluntad de las partes confluya en ellas, sin que baste, como sucede con las exclusiones generales, con que figuren en un documento expedido por la aseguradora ${ }^{30}$.

En estos supuestos, la confluencia de voluntades en exclusiones particulares se podrá evidenciar mediante cualquier mecanismo probatorio o, por lo menos, mediante un escrito o confesión según lo establece el art. 1046 del Código de Comercio ${ }^{31}$.

\section{(ii) Por el arbitrio concedido al asegurador para delimitar el riesgo que desea asumir}

Lo anterior es consonante con el art. 1056 del Código de Comercio que dispone que "el asegurador podrá, a su arbitrio, asumir todos o algunos de los riesgos a que estén

\footnotetext{
${ }^{29}$ La naturaleza técnica del contrato de seguro requiere que el asegurador lo celebre con muchísimos sujetos expuestos al mismo riesgo (Ossa, 1991, pp. 3-4).

30 Esta es la regla en los contratos celebrados haciendo uso de condiciones negociales generales, pues como lo indica HinESTROSA, es natural que "las cláusulas acordadas luego de deliberación se tomen como fruto genuino del querer de las partes, su prevalencia sobre las generales o estándar es apenas natural" (2015, p. 194).

31 La doctrina debate si la restricción probatoria establecida en el art. 1046 del Código de Comercio se limita a la prueba del contrato de seguro o se extiende a los elementos accidentales del mismo (OrDóÑEZ, 2001, pp. 52-57).
} 
expuestos el interés o la cosa asegurados, el patrimonio o la persona del asegurado", pues de indicarse que las exclusiones solamente pueden ser aquellas que figuren en las condiciones generales, se estaría restringiendo el arbitrio de la aseguradora a solo establecer exclusiones generales a todos los contratos de seguro que celebra, lo cual implicaría la imposibilidad de ajustar los contratos a aquellos casos que escapan de la cotidianeidad, limitándose gravemente de facto la posibilidad que tiene al aseguradora de delimitar los riesgos que asume.

\section{(iii) Por la finalidad informativa que tiene la regla bajo análisis}

Como lo evidencia la exposición de motivos de la Ley $\mathrm{N}^{\circ} 45$ de 1990, su finalidad era que la tomadora conociera o pudiera conocer la cobertura que se desprende del contrato de seguro celebrado. Esto de ninguna manera implica o conlleva que la aseguradora no pueda pactar exclusiones particulares.

Y es que la regla tiene sentido de cara a las exclusiones generales, pues estas se incorporan automáticamente al contrato sin discusión alguna (OssA, 1991, pp. 258-261) y por lo tanto es importante que el legislador procure que la tomadora tenga una verdadera oportunidad de conocerlas. No sucede así con las exclusiones particulares, las cuales, por su naturaleza requieren ser puestas de presente en la etapa de negociación con el fin de que sean aceptadas o no por la tomadora (JARAMILLO JARAMILLO, 2016b, pp. 87-89), lo cual implica que su eficacia estará necesariamente sometida a su conocimiento (Hinestrosa, 2015, p. 194).

\section{(iv) Paso de ser un contrato solemne a uno meramente consensual}

Estos argumentos se ven reforzados a partir del momento en que el contrato de seguro pasa de ser solemne a ser meramente consensual. Sobre este punto se pronunció el laudo del Nogal vs. Chubb al considerar que el cambio implicaba que bastaba con que la asegurada hubiese conocido y entendido el alcance de la cobertura para que la exclusión fuese eficaz. Puntualmente los árbitros indicaron que la mera consensualidad permitía el acuerdo de exclusiones por cualquier medio y que probadas estas dentro del proceso, esto es, probado que efectivamente en la negociación se había dispuesto y conocido por las partes que un determinado riesgo no estuviese cubierto, esto bastaría para dejar el evento desamparado, así no se hubiesen entregado las condiciones generales del contrato de seguro, o, habiéndose entregado estas, no figuraran las exclusiones en la primera página de la misma ${ }^{32}$.

\footnotetext{
32 A estos argumentos los árbitros añaden que el intérprete debe guiarse por el principio de la conservación del contrato o de la estipulación específica que se impugne, tratando de encontrar un entendimiento plausible de aquel o de esta que permita preservar su efectividad y poder vinculante (favori negocii), de tal manera que habrá de preferirse el sentido, según el cual lo acordado sea válido y eficaz, en vez de aquel que prive de efectos a lo convenido.
} 
Así, el que haya pasado a ser consensual refuerza la conclusión, pues pone de presente que el contrato de seguro, como los demás contratos, consiste en últimas en un acuerdo de voluntades y que, si bien existe regulación específica encaminada a que lo dispuesto en las condiciones generales o clausulado produzca efecto, esto no conlleva como consecuencia colateral que en casos particulares las partes no puedan hacer modificaciones a estas.

En palabras del art. 1618 del Código Civil "[c]onocida claramente la intención de los contratantes, debe estarse a ella más que a lo literal de las palabras", razón por la cual, si mediante un medio probatorio válido se logra demostrar que las partes habían acordado circunscribir el riesgo por medio de exclusiones específicas, la relación contractual y los efectos que de ella se desprendan, deben atenerse a lo acordado.

\section{(v) Disposición incluida por el Estatuto del Consumidor}

Por último, el art. 37 del Estatuto del Consumidor, regulando las condiciones negociales generales dispuso, de manera específica para el contrato de seguro, que la aseguradora debe entregar el clausulado a la tomadora antes de la celebración del contrato, explicándole, entre otros, el contenido de las exclusiones, so pena de ineficacia y de ser tenidas por no escritas.

De manera consecuente con lo que hasta aquí se ha expuesto, también debe entenderse que el nuevo Estatuto del Consumidor se está refiriendo a aquellas exclusiones contenidas en las condiciones negociales generales o clausulado. En el caso del Estatuto no queda duda alguna de que esto es así, pues de manera explícita se deja claro en el enunciado normativo; situación que considero refuerza las conclusiones a las que he arribado.

Así, lo que hace el Estatuto es incluir dos nuevos requisitos para la eficacia de las exclusiones establecidas en las condiciones generales: a) que el que el clausulado sea entregado anticipadamente y b) que las exclusiones sean explicadas. Pero esto tampoco es óbice para que se pacten otras exclusiones que consten en condiciones particulares de la póliza o en cualquier otro documento, exclusiones cuya eficacia, como ya se indicó, estará condicionada a que las partes efectivamente las hayan acordado.

\section{EL PROYECTO DE CÓDIGO CIVIL DE LA UNIVERSIDAD NACIONAL}

Finalizando esta investigación, la Universidad Nacional de Colombia, en compañía del Ministerio de Justicia, presentó a la comunidad una propuesta de Código Civil para remplazar el Código Civil y el Código de Comercio vigentes. Algunos de los artículos contenidos en la propuesta tocan con los puntos que desarrollo en este escrito, por lo tanto, antes de terminar, vale la pena analizar si estos ayudan a aclarar el panorama normativo que dio lugar a la desafortunada sentencia de 29 de enero de 2015. 
El art. 1416 del proyecto, al igual que el 1046 del Código de Comercio vigente, define la póliza como "el documento contentivo del contrato de seguro". Luego, el art. 1417 del proyecto reproduce el art. 1047 del Código de Comercio vigente, disponiendo que "[1]a póliza de seguro deberá expresar, además de las condiciones generales del contrato" las condiciones particulares tales como el nombre de las partes e interesados, la vigencia del contrato, la suma asegurada, la prima, los riesgos asumidos, etc. Sin embargo, dicho art. 1417 contiene dos parágrafos diferentes a los del 1047. Estos parágrafos disponen los siguiente:

Parágrafo $1^{\circ}$. En los casos en que no aparezca expresamente acordadas, se tendrán como condiciones del contrato aquellas de la póliza o anexo que el asegurador haya suministrado a la autoridad competente para el seguro pactado.

Parágrafo $2^{\circ}$. Los amparos y las exclusiones, ordenadamente, deberán ser consignadas a partir de la primera página de la póliza, en forma clara, concreta, sencilla y con caracteres destacados, evitando que el tamaño de la letra empleado impida u obstaculice la debida comprensión por parte del tomador, del asegurado o del beneficiario.

Las condiciones generales y particulares que limiten, restrinjan o afecten derechos del tomador, asegurado y beneficiario, o cuando liberen de responsabilidad al asegurador, o la atenúen, deberán aparecer en caracteres destacados. La autoridad competente velará por el estricto cumplimiento de tales deberes y, en general, en el ámbito propio de su competencia, por la observancia recíproca de los deberes de obrar de buena fe, de no abusar de los derechos propios y ajenos, de información razonable, de transparencia, de claridad, de cooperación o colaboración, de no sorprender y de coherencia y no contradicción, primordialmente.

Lamentablemente, el texto de la propuesta no elimina las confusiones y dificultades interpretativas de utilizar el término póliza para hacer referencia tanto a la sumatoria de documentos que contienen el contrato de seguro, como para hacer referencia a las condiciones negociales generales. De hecho, los dos párrafos del segundo parágrafo antes oscurecen aún más el panorama, pues en el primero de ellos se dice, en términos similares a los del EOSF, que los amparos y exclusiones deben figurar en la primera página de la póliza -lo cual debe estar refiriéndose, como he argumentado aquí, a las condiciones negociales generales- pero luego en el segundo párrafo se habla de las condiciones generales y particulares, pudiéndose dar a entender que estos documentos son diferentes de la póliza de la que se venía hablando. Dicho último párrafo, por lo menos, deja claro que en dichos documentos también se puede limitar la responsabilidad del asegurador.

Por su parte, el art. 1418 establece los siguientes nuevos criterios de interpretación:

Art. 1418. En la interpretación del contrato de seguro, además de los principios y reglas generales que rigen la materia, se observarán las siguientes pautas especiales: 1. En los amparos y exclusiones no tendrá cabida la analogía, ni su interpretación extensiva. 2. Las condiciones o cláusulas particulares, prevalecerán sobre las condiciones o cláusulas generales. Igualmente, primarán las manuscritas respecto de las preimpresas, y también los anexos y demás documentos complementarios frente a las condiciones generales. 3. En el evento de contradicción interna entre las condiciones generales, primarán las que, de acuerdo con la naturaleza específica del seguro celebrado y, en lo pertinente, con las circunstancias del caso individual, revelen de ma- 
nera más fidedigna la finalidad atribuida al respectivo contrato, teniéndose en cuenta, en lo aplicable, la confianza legítima inculcada por el asegurador, y las expectativas razonables del tomador, asegurado, o beneficiario. 4. Análoga regla se aplicará si la referida contradicción interna tiene lugar entre condiciones particulares. 5. En caso de ambigüedad, o de duda objetivas, las condiciones del contrato se interpretarán en contra de que aquél que las definió.

Este artículo, si bien ofrece criterios de interpretación útiles y que hasta ahora no habían sido positivizados ${ }^{33}$, tampoco resuelve la ambigüedad específica tratada en este escrito sobre qué debe entenderse por póliza para efectos de la norma que dispone que las exclusiones deben figurar en su primera página so pena de ineficacia.

Así, si bien algunas de las propuestas contenidas en estos artículos pueden constituir un avance en materia de interpretación, la reforma sería aún más provechosa si se aniquilara el problema de raíz indicándose que las exclusiones que deben figurar a partir de la primera página de la póliza son aquellas que van en las condiciones negociales generales, que este es el documento que en dichos contextos la ley ha denominado póliza, y que esto no es óbice para que las partes acuerden exclusiones particulares que serán válidas siempre y cuando sean consecuencia de un acuerdo consciente de las partes.

\section{CONCLUSIONES}

Comencé este análisis presentando un caso que había sido abordado por la Corte Suprema de Justicia. La problemática giraba en torno a la interpretación de la regla que establece que "las exclusiones deben figurar en la primera página de la póliza o en forma continua a partir de la primera página de la póliza" "so pena de ineficacia de la estipulación respectiva".

Mi propósito era identificar qué debe entenderse por póliza, cuáles son las exclusiones que deben figurar en su primera página, y qué sucedía con las que no cumplían este requisito. El análisis permitió concluir que la regla está regulando las condiciones negociales generales del contrato de seguro y que consecuentemente aplica únicamente a las exclusiones generales, pudiendo las partes acordar exclusiones particulares cuya eficacia no está condicionada a ningún formalismo.

En cuanto a las exclusiones generales, esto es, las que no son particularmente negociadas, estas, para ser válidas, sí deben figurar en la primera página del clausulado o a partir de esta de forma continua. Adicionalmente, de acuerdo con la regla introducida por el Estatuto del Consumidor, deben ser puestas en conocimiento y explicadas a la tomadora antes del perfeccionamiento del contrato. Aquellas exclusiones generales que no cumplan con estos requisitos serán ineficaces. Pero para las demás exclusiones (esto es, las particulares) bastará con que sean efectivamente acordadas entre las partes antes del perfeccionamiento del contrato.

\footnotetext{
33 Carlos Ignacio JaRAmillo (2016b) ha sostenido que estas reglas ya hacen parte de nuestro sistema jurídico a pesar de aún no haber sido explícitamente positivizadas.
} 
Lo anterior conlleva a que concluya que la decisión contenida en la sentencia de 29 de enero de 2015 de la Corte Suprema fue errada. El caso que tenía entre manos era uno de aquellos en los cuales la exclusión no estaba en las condiciones generales, sino por una exclusión acordada de manera particular por las partes y, por lo tanto, la regla aplicable no era la del art. 184.2 del EOSF, sino las reglas generales sobre el consentimiento y la formación de los contratos. Si la exclusión particular había sido pactada - como el anexo parece indicar que lo fue-era entonces válida y podía y debía ser tenida en cuenta en la resolución de la disputa contractual.

\section{BIBLIOGRAFÍA}

\section{A. Doctrina}

Barnett, R. E. (1986). Consent Theory of Contract. Columbia Law Review, 86(2), 269-321.

BARnett, R. E. (2002). Consenting to Form Contracts. Fordham Law Review, 71(3), 627-646.

Díaz Lindao, I. (2012). Límites a las cláusulas modificativas de la responsabilidad en el derecho moderno de los contratos. Revista de Derecho Privado, 139-190.

Hinestrosa, F. (2015). Tratado de las obligaciones II: de las fuentes de las obligaciones: el negocio jurídico (Vol. II). Bogotá D.C.: Universidad Externado de Colombia.

Hinestrosa, F. (2015). Tratado de las obligaciones II: de las fuentes de las obligaciones: el negocio jurídico (Vol. I). Bogotá D.C.: Universidad Externado de Colombia.

Jaramillo Jaramillo, C. I. (2016a). Principios rectores y reglas de interpretación de los contratos. Bogotá D.C.: Ibáñez.

JARAMILLO JARAMILLO, C. I. (2016b). La regla de la 'prevalencia de las condiciones particulares sobre las condiciones generales'. su proyección en el ámbito de la interpretación de los contratos, y en especial en el contrato de seguro. Revista Ibero-Latinoamericana de Seguros, 45(25), 59-103.

KeSSLER, F. (1943). Contracts of adhesion--some thoughts about freedom of contract. Columbia Law Review, 43(5), 629-642.

Klass, G., Letsas, G., \& Saprai, P. (Edits.). (2014). Philosophical Foundations of Contract Law. Nueva York: Oxford University Press.

LefF, A. A. (1970). Contract as thing. American University Law Review, 19(2), 31-157.

LEFF, A. A. (1970). Unconscionability and the crowd consumers and the common law tradition. University of Pittsburgh Law Review, 31(3), 349-358.

OrdóñEZ, A. (2001). Lecciones de derecho de seguros N. 1: cuestiones generales y caracteres del contrato. Bogotá D.C.: Universidad Externado de Colombia.

Ospina Fernández, G. (2005). Teoría general del contrato y del negocio jurídico. (E. Ospina Acosta, Ed.) Bogotá D.C.: Temis.

Ossa, J. E. (1991). Teoría general del seguro: el contrato (Segunda ed.). Bogotá D.C.: Temis. 
PosAdA, C. (2015). Las cláusulas abusivas en los contratos de adhesión en el derecho colombiano. Revista de derecho privado(29), 141-182.

Rakoff, T. D. (1983). Contracts of Adhesion: An Essay in Reconstruction. Harvard law Review, 96(6), 1173-1284.

\section{B. Jurisprudencia}

Corte Suprema de Justicia, sentencia de 19 de diciembre de 2008, M. P. Arturo Solarte Rodríguez, ref.: 11001-3103-012-2000-00075-01.

Corte Suprema de Justicia, sentencia de 25 de julio de 2013, M.P. Margarita Cabello Blanco, exp. 01591-00.

Corte Suprema de Justicia, sentencia de tutela de 29 de enero de 2015, M.P. Margarita Cabello Blanco, STC514-2015.

Corte Suprema de Justicia, sentencia de 18 de marzo de 2015, M.P. Luis Gabriel Miranda Buelvas, STL3392-2015.

Corte Suprema de Justicia, sentencia de 25 de octubre de 2017, M. P. Ariel Salazar Ramírez, STC17390-2017.

Corte Suprema de Justicia, sentencia de 13 de diciembre de 2017, M. P. Luis Gabriel Miranda Buelvas, STL21422-2017.

Corte Suprema de Justicia, sentencia de 10 de octubre de 2018, M. P. Octavio Augusto Tejeiro Duque, STC13117-2018.

Corte Suprema de Justicia, sentencia de 04 de febrero de 2019, M. P. Octavio Augusto Tejeiro Duque, STC941-2019.

Tribunal Superior de Bucaramanga, sentencia de 8 de mayo de 2013, M. P. Mery Esmeralda Agón Amado, rad. 68001-31-03-010-2009-00364-01.

Tribunal Superior de Bucaramanga, sentencia de 29 de mayo de 2013, M. P. Claudia Yolanda Rodríguez Rodríguez, rad. 2010-0029-01.

\section{Laudos arbitrales}

Laudo "Corporación Club el Nogal vs. Chubb de Colombia Compañía de Seguros S.A., y Mapfre Seguros Generales de Colombia S.A." de 15 de marzo de 2006.

Laudo “C.I. Avetex S.A. v. BBVA Seguros Colombia S.A.” de 5 de diciembre de 2008.

\section{Conceptos}

Superintendencia Financiera de Colombia en concepto 1999055614-2 de 9 de febrero de 2000. 
Superintendencia Financiera de Colombia en concepto 19980446555 de 17 de agosto de 1999.

Superintendencia Financiera de Colombia en respuesta de 4 de febrero de 2020 a una consulta específica, rad. 2019153273-007-000. 